\title{
Investigating the Acceptance of Mobile Health Application User Interface Cultural-Based Design to Assist Arab Elderly Users
}

\author{
Ahmed ALsswey, Irfan Naufal Bin Umar, Brandford Bervell \\ Center for Instructional Technology and Multimedia, Universiti Sains Malaysia, \\ Pulau Penang, Malaysia
}

\begin{abstract}
Mobile health (m-health) applications are a way to provide solutions to the non-availability of physical health services in the Arab world. However, end users of m-health around the world have their cultural and personal differences that distinguish them from others. Studies suggest that culture is an essential component of the success of any product or technology usage. In view of this, the study investigated acceptance towards mobile health application User Interface (UI) designed for Arab elderly users based on their culture. The TAM model formed the theoretical basis upon which a quantitative design was adopted, with a questionnaire as data collection instrument from 134 participants. The findings showed that perceived Ease of Use (PEOU) and Attitude Towards Use (ATU) had a significant positive influence on Behavioural Intention (BI) to use mobile health application User Interface. Overall, the results indicated that Arab elderly users found the mobile health application UI as acceptable due to its cultural-based design. To improve designs of mobile applications UI targeting elderly users, it is vital to gain insight into cultural aspects that influence the usability of mHealth application UI as well as insights into their personal characteristics and experiences.
\end{abstract}

Keywords-TAM; elderly users; mobile health applications; user interface; culture

\section{INTRODUCTION}

Recently, the number of aged people over 65 years old has increased rapidly in the world and it is predicted to be about 1 billion by 2030 [1]. The significant increasing number of elders suggests the need to develop technologies for this group of users, in order to achieve their health demands [2], [3]. For example, the number of elderly generation aged 65 years and over in the United States is expected to rise from 40 million in 2010 to 72 million in 2030 [4]. This means that there should be more friendly and usable technologies developed to provide healthcare related support for this elderly population, as pressure on physical health facilities will be eminent.

Currently, it was reported in January 2018 that within the world, approximately 2.51 million times mobile health- apps (health and fitness) available in the Google Play Store were downloaded to mobile devices (https://www.statista.com/statistics/699096/leadinghealth-andfitness-google-play-canada-downloads/). These health apps involved numerous types of medical and health applications such as health and fitness apps for life management, medical education and patient-centered apps [5]. With the rapid increase in health apps, research on their use in the areas of healthcare evaluation, medicine and disease management have also increased meaningfully in the last years [6]. A large number of studies carried out on mobile apps concentrated on particular medical issues such as pain management [7], weight loss [8], [9], and diabetes [10], [11]. To analyze the content of applications and provide deep vision into what apps are presented and what practice based theories inform app design approach is of deep concern. In view of this, it is important to go behind content analysis to investigate users' perceptions towards m-health apps user interface (UI). Investigating users' experience with current m-health apps to give opportunity for researchers and apps developers to better design future mhealth apps to be usable, effective and accepted by end users is becoming important. This is culturally possible when culture sophistication in design of such apps is to be addressed.

However, there is a lack of empirical studies that investigate and validate the effect of culture on UI design in Arab countries within the m-health context. Poor cultural aspects in UI design regularly means poor user interaction and hence reduced user acceptance and satisfaction.Therefore, addressing cultural differences of use in designing User Interfaces (UIs) could improve acceptance, usability and help users to interact in a better way with the interface. In addition, elderly users are not the main target of design technology and mobile applications [12]. This study contributes towards understanding Arab elderly users' attitudes towards using mhealth application UI designed based on their cultural elements and the factors that influence users' intentions to use the designed mobile health application. In addition, recognizing and addressing these factors will support future design of mobile health applications UI and their implementation in the Arab world. The remainder of this paper is structured as follows. Section II describes the literature review of this study. Section III presents the research methodology. Section IV presents the results and analysis. Section V discusses the results of the study. Section VI presents conclusion and implications. Section VII describes the limitations of the study. Section VIII presents the future work. 


\section{LITERATURE REVIEW}

\section{A. Possible Barriers Faced by Elderly users in using Technology}

One of the explanations for the seeming lack of m-health applications targeting Arab elders, is the lack of studies carried out to investigate the factors that affect elderly users' engagement in technology, to inform developers on the suitable m-health application appropriate for the Arab aged population [13]. On the other hand, there is the general idea in the world that the elderly are unwilling, unable and afraid to use technology involving mobile phones, internet and computers [14]-[16]. In addition, some elderly folks suffer from some effects of ageing such as hearing loss, psychomotor impairments, diminished vision as well as reduced attention, memory and learning abilities occurring at the beginning of ageing or resulting from some form of disease. These serve as barriers to interacting with technology. This may prevent them to effectively use technologies such as mobile applications, internet and navigating websites [17]. Around the world, the age group of 50 years and above suffer from some form of physical limitations and mental changes that can cause an interference with their engagement with technology [16]. In view of this, within the Arab context, there is the need to provide an m-health application coupled with an ideal environment that foster the engagement of elderly people aged 60 years and above with technology to improve upon their health behavior.

\section{B. Elderly Users and Mobile Health Apps}

According to [18], within The Netherlands, there has been an increasing interest among older people in using technology such as computers, smartphones and the internet. The search for health information and healthcare services is one of the most priorities for this group of users. One technology to deliver such health related services for elderly users is mobile technology, referred to as mobile health (m-Health). In addition, mobile health technologies have the ability to promote care to the elderly users through easy use and convenient healthcare. For instance, m-Health applications can remind patients to take medications, track daily pain levels, watch symptom levels and have access to behavioural health information $[19,20]$. As the elderly lives longer, there is the need to improve their live through care and support by using technologies that adapt to ageing changes for better technology usable experience. M-health applications can provide such vital opportunities to learn and obtain health information to improve their lives [21].

\section{Arab Elderly Users}

The Arab world has witnessed rapid growth in the number of older adults. Based on the latest statistics in 2017, the older adults were 26.8 million in 2015 and expected to be 50 million by 2030 . Presently, the percentage of elderly aged 60 years and above in the Arab world is expected to be $6.7 \%$, with projections showing an increase to $9.5 \%$ by 2030 [22]. Therefore, the responsibility of the workforce is expected to change from the usual support for children, to the simultaneous support for both children and older persons [23]. This makes it expedient to develop technologies targeted at Arab elderly users to primarily support their healthcare and reduce the envisaged dependency on the working class, while addressing the issue of non-availability of physical healthcare services. However, these mobile health technologies should be more convenient and acceptable for such people.

\section{Arab Culture}

Generally, end users around the world have their cultural and personal differences such as the customs, religion, habits and different languages that distinguish them from others. In addition, they interact using technology in different manners, depending on these differences [24]. In view of this, designing mobile applications' user interface to be more user friendly is a vital issue for the success of such applications, technologies and products. Nonetheless, the user interfaces in mobile phones face cultural differences, which mean that interfaces should be more convenient and acceptable to each cultural attribute [25].

The principles of Arab culture are special and unique, often unclear and secretive to Western cultures. Arab cultures are traditional, whereas the term Arab refers to language and cultural aspects, with many practices and norms revolving around Islamic beliefs and customs. So, everyday words, images, symbols or phrases that may be completely acceptable in western countries may be unacceptable for Arab audience [26]. Therefore, considering these differences in the UI design might be important for improved acceptance towards usability of UIs. This study designed a mobile health application UI based on Arab culture to enhance acceptance of using mHealth app UI.

\section{E. Theoretical Framework and Development of Research Hypotheses}

Several models have been suggested by researchers to investigate the individual acceptance behaviour on information technology and information systems, for examples of such models include Theory of Reasoned Action (TRA), [27], Theory of Planned Behaviour (TPB), [28]. Technology Acceptance Model (TAM, TAM2, and TAM3), [29], and Unified Theory of Acceptance and Use of Technology (UTAUT), [30]. Technology Acceptance Model (TAM) is one of the most popular theories used widely to investigate the individual acceptance behaviour of information systems [31]. TAM model as shown in Fig. 1, comprises variables such as behavioural intention to use, attitude towards use, perceived usefulness and perceived ease of use [32]. Davis (1989) defines perceived usefulness as the prospective user's subjective probability that using a specific application system will enhance his or her job or life performance, while perceived ease of use defines the degree to which an individual believes that using a particular system would be free of mental or physical effort. Additionally, behavioural intention is defined as "the strength of one's intention to perform a specified behaviour" [31]. Attitude on the other hand can be defined as "an individual's positive or negative feelings about performing a target behaviour" [33]. Previous reviews show that TAM may assist as a useful theoretical framework for the present study. Particularly, TAM provides its strength in predicting behavioural intention [34], [35]. 


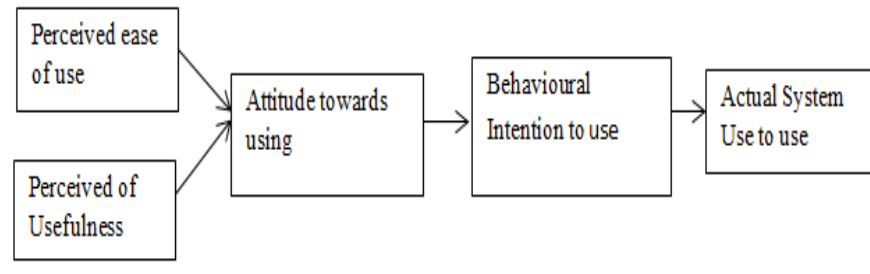

Fig. 1. Technology Acceptance Model (TAM) Davis (1989).

1) Relationship between perceived ease of use (PEOU) and perceived usefulness (PU): Perceived ease of use is expected to have a positive influence on perceived usefulness. The findings of the original TAM model have shown that perceived ease of use has a positive effect on perceived usefulness. Studies conducted by Gambari, and Sule [36], Liu [37] show that users do well in tasks when they do not need to exert much mental and physical effort. This study defines ease of use as the degree to which Arab elderly users' usage of mHealth app UI is perceived or seen as easy or effortless. Hence, this study hypothesizes that:

H1: Perceived ease of use will have a positive effect on user Perceived usefulness.

2) Relationship between perceived usefulness (PU) and attitude: Based on TAM studies, the first primary relationship is that perceived ease of use and perceived usefulness will have a possible impact on enhancing users' attitude towards usage. In addition, Juniwati [38] indicates that both perceived ease of use and perceived usefulness may affect attitude. Alsamydai [39] posited that, perceived usefulness was an important factor in using mobile banking services. It is supposed that perceived usefulness was affected by the level of users' trust [40]. Lai and Yang [41] claimed that users in a performance-oriented e-business environment are usually reinforced for good performance and benefits. Hence, this study defines usefulness as the degree to which Arab elderly users' usage of mHealth app UI is perceived as useful or beneficial. This notion will positively influence attitude toward mHealth app UI. Consequently, this study hypothesized that:

H2: Perceived usefulness will has positive effect on Attitude to use mHealth app UI.

3) Relationship between perceived ease of use (PEOU) and attitude: Attitude towards actual usage is determined by a belief of how easy the user thinks he can use the system. TAM posits that PEOU has a direct positive influence on attitude towards using a system. The present studies propose that perceived ease of use is a main attribute in defining the attitude of an individual towards system usage. This study defined attitude as the overall affection (whether positive or negative) of Arab elderly users towards using mHealth applications UI. Positive attitude is acquired when Arab elderly users find as easy when they use mHealth app UI. The reverse will be the case. This usually depends on the effort needed to use the application and the complexity of the process. Therefore, this study hypothesizes that:

H3: Perceived ease of use will has positive effect on user attitude to use mHealth app UI.

4) Relationship between perceived usefulness (PU) and behavioural intention (BI): Davis [29] defined perceived usefulness (PU) as the users' belief that using a particular system will increase his or her job performance. Based on this definition, Phua, Wong, and Abu [42] found PU as a main factor of usage behaviour and intention. Subramanian [43] found that PU (not PEOU), had a direct impact on usage behaviour. This study, define PU as the degree to which Arab elderly users believe that the use of mHealth app UI will improve their health related needs or livelihood. Consequently, this study hypothesizes that:

H4: Perceived usefulness will has positive effect on user behavioural intention to use mHealth app UI.

5) Relationship between perceived ease of use (PEOU) and behavioural intention (BI): Perceived ease of use (PEOU) has an indirect impact on behavioural intention to use technology through increased perceived usefulness [44]. The easier a system is to interact with; the greater should be the users' sense of efficacy [45] and personal control [46], concerning his or her ability to move out the sequences of behaviour required to run the system. This study defines PEOU as, flexibility, simplicity and compatibility towards the overall usage of the mobile health application as experienced by Arab elderly users. Subsequently, the variables attached to perceived ease of use (flexibility, simplicity and compatibility) were all positively related to behavioural intention in the literature. Hence, this study hypothesizes that:

H5: Perceived ease of use will have a positive effect on behavioural intention to use mHealth app UI.

6) Relationship between attitude and behavioural intention (BI): Attitude (ATU) is a vital construct in the domain of information technology. In terms of mobile applications, most users today prefer to use mobile apps for various purposes because of their portability characteristics. Based on their previous experiences, they develop an attitude towards using them, ranging from good to poor. Previous empirical studies have shown the existence of such generalized attitude and its effects on the assessment of new systems in similar situations [47]-[49]. In this study, attitude is envisaged to have effects on intention towards using mHealth app UI. The variable is defined in this study as the degree to which Arab elderly users have favourable or unfavourable affection towards using mHealth app UI. Numerous studies such as that of Shittu, Gambari, and Sule [36] and Wang and Liu [50] have stated that the attitude construct affect behavioural intention. This study posits that how favourable or unfavourable Arab elderly users perceive the use of mHealth applications UI to be, will eventually influence their intention behaviour to use the application. Against this backdrop, they study hypothesizes that: 


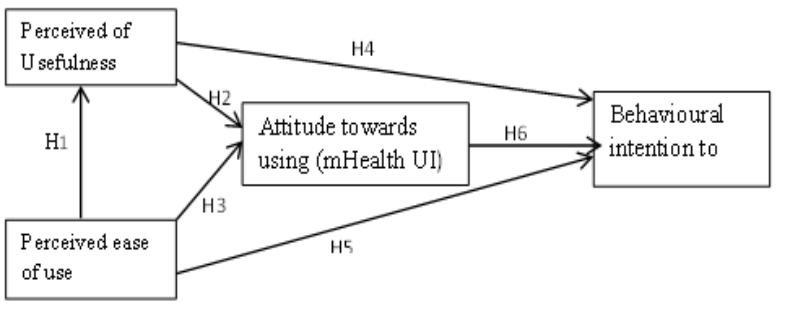

Fig. 2. Conceptual framework.

H6. Attitude towards use will have a positive effect on behavioural intention to use mHealth app UI. The conceptual framework based on this discussion is presented in Fig. 2.

\section{F. Mobile Health Application based on Arab Culture}

A mobile health application was specifically developed for Arab elderly users for this study. The application manages their health related information and needs such as dosage, time, type of medicine and instructions about medication. In addition, this application provides general health related information on the causes, symptoms and preventive strategies of diseases specific or common to the Arab world. Fig. 3 depicts a graphical image of the interfaces for this mobile health application.

Arabic language used in designing this app UI was to ensure that the functions are clear and understandable for Arab elderly users from different backgrounds to avoid any confusion that can occur due to different meaning of some local terms and words. Colours of Arab culture and Islam (green, blue and black) are used in designing app UI to enhance acceptance of Arab users, since Arab people are proud of their culture, customs, and religion. Green reflects the Islamic symbol, while black is linked to a specific period of time in the Islamic era. The Blue colour is related to the sea and sky. Red and yellow colours also used in designing the application UI were to attract the users. Since these colours are used frequently in the Arab world to get the attention of users and attract them to try its usage and buy different things such as clothes, foods, cars etc.

The app UI used font size of 12pt and font type "الرقعة to display the information while font size $14 \mathrm{pt}$ was used for heading. This is because it is one of the easiest Arabic fonts and the most widespread among people in their daily writings. Additionally, its simplicity and distance from the complexity and ease of reading and writing are very much appreciate in the Arab world [51]. Information architecture of app UI was designed simply based on previous studies conducted on Arab culture such as by Hall [52] and Hofstede [53]. They showed that Arab culture is Uncertainty Avoidance culture, which means that Arab people do not like risk, and prefer simple use and avoid any complex design of systems.

Arab culture has strong Individualism and Collectivism dimension [52], [53]. This means that Arab users have high concern for the group and exchange for devotion. Reputation, dignity, shame, honour, and pessimism occupy a higher consideration. Therefore, common Arab icons and symbols are used in the app UI design. In addition, Arab writing and reading are from right to left. Therefore, the UI layout was designed from right to left. Finally, labels and messages were used in the app UI design to inform users about the various stages of usage and completed tasks. This was targeted at providing easy assistance and information on progress made with the system's use.

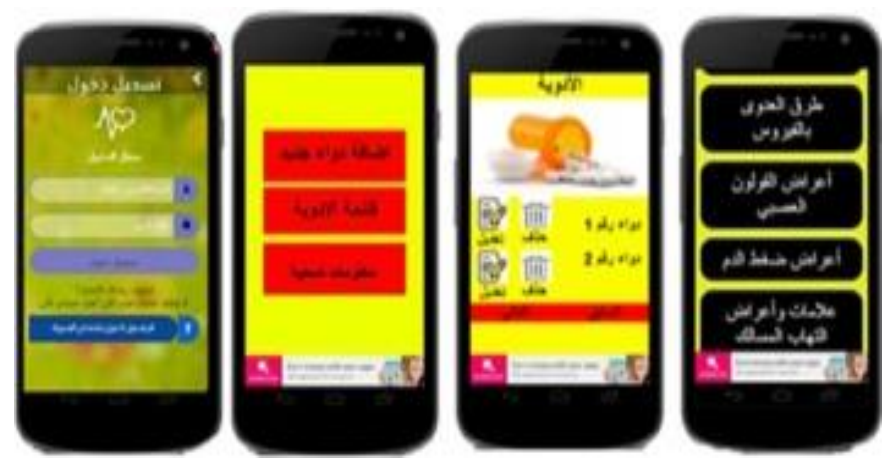

Fig. 3. Some Screen Shoot of the Designed mHealth App.

\section{RESEARCH METHODOLOGY}

\section{A. Ressarch Method}

1) Questionnaire: The questionnaire for this study was adopted from Davis (1989) and modified to suit mobile health app UI context which have also been validated in previous studies such as Ntaliani, Costopoulou [54], Alharbi and Drew [32], to guarantee clarity and avoid grammatical and language errors, the questionnaire was first examined by English language experts and then translated into Arabic language by Arabic language experts. This provided clarity and accuracy of understanding to the respondents. This is because the respondents were native Arabic speakers.

2) Instrument: The questionnaire consisted of five parts. Part one focused on demographic characteristics of participants. Parts two, three, four and five elicited responses on factors related to TAM model constructs. Specifically, parts two and three measured participants' Usefulness, Ease of Use toward using m-health application UI respectively, while part four measured the factors that impact users' Attitude and part five on Behavioural Intention to use mobile health app UI. All TAM factors were measured at five levels of Likerttype scale. Participants were asked to choose from 5 points Likert-type scale with $1=\mathrm{SD}$ (Strongly Disagree), 2= D (Disagree), 3= N (Not Sure), 4= A (Agree) and 5= SA (Strongly Agree).

3) Sample and data collection: In this study, the target population was Arab elderly users (male and female) from different backgrounds aged 60 years and above and have at least one year experience in using mobile applications. This study used purposive sample technique to obtain the sample size for this study. 150 questionnaires were distributed but a total of 137 questionnaires were received from the targeted respondents, which constituted $91.3 \%$ response rate from the survey. Among the 137 sets of questionnaires returned, there were incomplete responses from four respondents, leaving 134 questionnaires for further data analysis use. 


\section{DATA ANALYSIS}

\section{A. Demographics}

Demography of participants for the study was analysed by simple descriptive statistics. Results from this analysis are depicted in Table I.

TABLE I. DEMOGRAPHIC INFORMATION STATISTICS FOR PARTICIPANTS

\begin{tabular}{|l|c|c|c|}
\hline & Information & $\begin{array}{l}\text { Number of } \\
\text { participants }\end{array}$ & $\begin{array}{l}\text { Percentage of } \\
\text { sample }\end{array}$ \\
\hline Age & $60-64$ & 118 & $88.1 \%$ \\
& $65-69$ & 10 & $7.5 \%$ \\
& $70-74$ & 4 & $3.0 \%$ \\
& $75-79$ & 2 & $1.5 \%$ \\
\hline Participants' & $\geq 80$ & 0 & $0 \%$ \\
Gender & Male & 113 & $84.3 \%$ \\
\hline & female & 21 & $15.7 \%$ \\
Participants' & School level & & $43.3 \%$ \\
Level of & Diploma & 58 & $32.8 \%$ \\
Education & Bachelor & 44 & $11.2 \%$ \\
& Master & 8 & $6.0 \%$ \\
& degree & 9 & \\
\hline Participants' & PhD degree & & $15 \%$ \\
experience level \\
of mobile apps
\end{tabular}

As shown in Table I, majority of respondents were between the age range of $60-64$ years (n: $118 ; 88.1 \%)$. However few of them (n: $2 ; 1.5 \%$ ) were between $75-79$ years old. None of the participant was 80 years or above. Regarding the gender, out of the 134 respondents, 113 of them $(84.3 \%)$ are male and 21 $(15.7 \%)$ are female. With regards to the level of education, most of the respondents had school level certificate (n: 58; $43.3 \%$ ). A few of them possessed masters (n: $8 ; 6.0 \%$ ) and Ph.D. (n: 9; 6, 7\%). In terms of experience in mobile application usage, majority of the users.

\section{B. Instrument Reliability}

Reliability is the consistency of measurement or stability of measurement over a variety of conditions in which basically the same results should be obtained [55]. The reliability analysis was based on the Cronbach's Alpha tests on the items used for each factor. Table II shows the reliability of each factor of this study.

TABLE II. RESULTS OF RELIABILITY ANALYSIS

\begin{tabular}{|l|l|l|}
\hline Factor & Items & Cronbach's alpha \\
\hline $\begin{array}{l}\text { Perceived Usefulness } \\
\text { (PU) }\end{array}$ & 6 & .878 \\
\hline Ease of use (EOU) & 7 & .796 \\
\hline Attitude (AT) & 4 & .725 \\
\hline $\begin{array}{l}\text { Behavioural Intention } \\
\text { (BI) }\end{array}$ & 3 & .703 \\
\hline $\begin{array}{l}\text { Overall reliability of } \\
\text { Acceptance factors }\end{array}$ & 20 & .897 \\
\hline
\end{tabular}

Reliability values can be classified into four ranges: values of up to 0.50 indicate low reliability; values from 0.50 to 0.70 indicate moderate reliability; and values from 0.70 to 0.90 indicate high reliability respectively [56]. The findings shown in Table II indicate that all reliability values were higher than 0.70 which is considered as high. Moreover, when all items were entered at the same time, the overall reliability for this instrument was 0.897 , exceeding the acceptable threshold.

\section{Acceptance Correlation Analysis}

The correlation coefficients were examined to determine the relationship between Perceived ease of use (PEOU), Perceived Usefulness (PU), Attitude (AT) and Behavioral Intention (BI) toward mobile health application UI usage. Pearson's correlation analysis was employed, since it is the most common measure of correlation which shows the degree of linear relationship between variables and it is useful for scale and interval variable relationships [57]. Table III shows the correlations between the PEOU, PU, AT, and BI.

Table III shows that the correlations between acceptance factors PEOU, PU, AT and BI are significant and positive. Based on Pearson correlation 1 to 0.3 represents small; 0.3 to 0.5 medium; and 0.5 to 1.0 large [58]. Table III shows there is a moderate significant positive correlation between perceived ease of use and perceived usefulness $\left(\mathrm{r}=0.379^{*}, \mathrm{p}<0.01\right)$. Additionally, the results indicated that there is a moderate significant positive correlation between perceived usefulness and attitudes towards using the mobile health application UI ( $\mathrm{r}$ $\left.=0.345^{* *}, \mathrm{p}<0.01\right)$. Furthermore, the findings show that there is a large significant positive correlation between perceived ease of use and attitudes towards using the mobile health app UI $\left(r=0.760^{* *}, p<0.01\right)$. Similarly, the relationship between attitude towards using the mobile health app and Behavioral Intention was significantly positive and large $\left(\mathrm{r}=0.641^{* *}\right.$, $\mathrm{p}<0.01)$.

TABLE III. PEARSON CORRELATION BETWEEN VARIABLES

\begin{tabular}{|l|l|l|l|l|}
\hline Factors & $\begin{array}{l}\text { Behavioural } \\
\text { Intention (BI) }\end{array}$ & $\begin{array}{l}\text { Attitude } \\
(\mathbf{A T})\end{array}$ & $\begin{array}{l}\text { Ease of } \\
\text { use } \\
\text { (EOU) }\end{array}$ & $\begin{array}{l}\text { Perceived } \\
\text { Usefulness } \\
\text { (PU) }\end{array}$ \\
\hline $\begin{array}{l}\text { Behavioural } \\
\text { Intention (BI) }\end{array}$ & 1 & $\begin{array}{l}.641^{* *} \\
.000\end{array}$ & $\begin{array}{l}.622^{* *} \\
.000\end{array}$ & $\begin{array}{l}.322^{* *} \\
.001\end{array}$ \\
\hline Attitude (AT) & $\begin{array}{l}.000 \\
.641^{* *}\end{array}$ & 1 & $\begin{array}{l}.760^{* *} \\
.000\end{array}$ & $\begin{array}{l}.345^{* *} \\
.001\end{array}$ \\
\hline $\begin{array}{l}\text { Ease of use } \\
\text { (PEOU) }\end{array}$ & .000 & $\begin{array}{l}.002^{* *} \\
.000 * *\end{array}$ & 1 & $\begin{array}{l}.379^{* *} \\
.000\end{array}$ \\
\hline $\begin{array}{l}\text { Perceived } \\
\text { Usefulness } \\
\text { (PU) }\end{array}$ & $.322^{* *}$ & .001 & $\begin{array}{l}.345^{* *} \\
.001\end{array}$ & $.379 * *$ \\
.000 & 1 \\
\hline
\end{tabular}




\section{Factors Affecting Arab Elderly Users' Behavioural Intention of using Mobile Health Application UI}

To find the factors affecting Arab elderly users' acceptance of using mobile health application UI, stepwise multiple regression was conducted. Before continuing for the regression analysis, suitability of the regression analysis was assessed to ensure that there was no violation of the assumptions of outliers, normality, multi-collinearity, homoscedasticity, linearity, and independence of residual. Based on Kock [59], in assessing multi-collinearity among variables, the best approach is to analyze the variance inflation factor (VIF) values. Accordingly, VIF values below 3.0 indicate the absence of multi-collinearity. Based on the result for this study, all VIF values for the relationships between dependent and independent variables ranged from 1.000 to 2.258 which are below the 3.0 threshold [61]. The VIF values for dependent variables are shown in Table IV.

TABLE IV. MULTI-COLLINEARITY STATISTICS VIF

\begin{tabular}{|l|l|l|l|}
\hline \multirow{2}{*}{$\begin{array}{l}\text { Independent } \\
\text { Variables }\end{array}$} & \multicolumn{3}{|l|}{ Dependent Variable } \\
\cline { 2 - 4 } & Behavioural & Attitude & Usefulness \\
\hline Ease of use & 1.857 & 1.065 & 1.000 \\
\hline Usefulness & 1.312 & 1.065 & \\
\hline Attitude & 2.258 & & \\
\hline
\end{tabular}

E. Multiple Regressions between Perceived Ease of Use, Usefulness, Attitude and Behavioural Intention

A multiple regression was finally applied to test for predictive significance between dependent and independent variables. The results of the stepwise regression are presented in Table V.

TABLE V. ANOVA Results Between Perceived EASE of Use, USEFULNESS, ATTITUDE AND BEHAVIOURAL INTENTION

\begin{tabular}{|l|l|l|l|l|l|}
\hline No. & Model & $\begin{array}{l}\text { Sum of } \\
\text { Squares }\end{array}$ & df & $\begin{array}{l}\text { Mean } \\
\text { Square }\end{array}$ & F \\
\hline 1. & Regression & 6.331 & 1 & 6.331 & 55.134 \\
& Residual & 9.071 & 79 & .115 & \\
\hline & Total & 15.402 & 80 & & \\
2. & Regression & 6.992 & 2 & 3.496 & \\
& Residual & 8.410 & 78 & .108 & 32.424 \\
\hline
\end{tabular}

Dependent Variable: Behavioral Intention Predictors: (Constant), Attitude

Predictors: (Constant), Attitude, Ease of use

Table V shows ANOVA, a test of significance of model. The results show that two predictor variables (ease of use and attitude) are a statistically significant predictors of behavioural intention in using mobile health application UI. Table VI shows the values of regression coefficients of the two regression models constructed by stepwise regression method. Two independent variables emerged as positive predictors of behavioural intention.
TABLE VI. VALUES OF MULTIPLE LINEAR REGRESSION BETWEEN PERCEIVEd USEFulNess, PERCEIVED EASE OF USE, ATtITUde AND BEHAVIOURAL INTENTION

\begin{tabular}{|c|c|c|c|c|c|}
\hline \multirow[t]{2}{*}{ Model } & \multicolumn{2}{|c|}{$\begin{array}{l}\text { Unstandardized } \\
\text { Coefficients }\end{array}$} & \multirow{2}{*}{$\begin{array}{l}\begin{array}{l}\text { Standardized } \\
\text { Coefficients }\end{array} \\
\text { Beta } \\
\end{array}$} & \multirow[t]{2}{*}{$\mathbf{t}$} & \multirow[t]{2}{*}{ sig } \\
\hline & $\mathrm{B}$ & Std. Error & & & \\
\hline $\begin{array}{l}\text { Behavioural } \\
\text { Intention } \\
\text { (Constant) }\end{array}$ & $\begin{array}{l}1.394 \\
.629\end{array}$ & $\begin{array}{l}.964 \\
.391 \\
.344\end{array}$ & .641 & $\begin{array}{l}3.777 \\
7.425\end{array}$ & $\begin{array}{l}.000 \\
.000\end{array}$ \\
\hline $\begin{array}{l}\text { Attitude } \\
\text { Ease of use } \\
\text { (Constant) }\end{array}$ & $\begin{array}{l}.964 \\
.391 \\
.344\end{array}$ & $\begin{array}{l}.397 \\
.126 \\
.139\end{array}$ & $\begin{array}{l}.399 \\
.319\end{array}$ & $\begin{array}{l}2.425 \\
3.094 \\
2.476\end{array}$ & $\begin{array}{l}.018 \\
.003 \\
.015\end{array}$ \\
\hline $\begin{array}{l}\text { Usefulness } \\
\text { (Constant) }\end{array}$ & .255 & .084 & .322 & 3.021 & .003 \\
\hline
\end{tabular}

The Behavioural Intention of Arab elderly users was primarily determined in a positive manner by Ease of Use $(\beta=$ $0.319, \mathrm{p}<0.05)$, Attitude $(\beta=0.399, \mathrm{p}<0.05)$, and Usefulness $(\beta=0.322, p<0.05)$. Apparently, Attitude was the strongest predictor in affecting the Behavioural Intention in using mobile health application user interface. The Attitude of Arab elderly users was in turn influenced by ease of use $(\beta=0.319, \mathrm{p}<$ $0.05)$ and strongly determined by Usefulness $(\beta=0.322, p<$ 0.05). However Arab elderly users' perception of the usefulness of the mobile health app was based on easiness of use of the application $(\beta=0.322, \mathrm{p}<0.05)$.

\section{DISCUSSION}

The findings of this study showed that Arab elderly users have positive intentions to use the designed mHealth app UI. TAM constructs (attitude, usefulness, and ease of use) had high prediction levels in explaining behavioural intention to use mobile health app UI. Ultimately, the construct attitude was the strongest predictor of the mHealth UI app uptake intention. This means that the sample population had a positive attitude toward using mobile health app UI which was designed based on their culture. This induced positive attitudes towards their use of the application in the future. Consequently, the majority of Arab elderly users believed that using mobile health app UI was also positive and a good idea. This finding supports studies such as that of Alotaibi, Houghton [60] and Fong and Wong [61] who found that the mainstream of participants wanted to use mobile application and services based on their positive attitude toward the application.

Additionally, ease of use had a strong significant positive relationship towards attitude to use the mobile health app. This indicates that the mobile health app UI design was clear, simple and easy to use. This was because the consistency between UI elements designed based on Arabic aspects such as language, layout, colors, and buttons promoted ease of use. These findings are supported by several studies that found perceived ease of use to have a close correlation to the construct attitude in TAM [42], [62]. In addition, the result of this study is supported by other studies conducted on the role 
of culture in technology design such as that of Almakky, Sahandi [63], Ishak, Jaafar [64] and Kalliny, Saran [26]. These previous researchers also addressed the fact that users feel it is easy to interact with technologies and user interfaces which directly reflect and relate to their own culture. Furthermore, perceived ease of use had a strong significant relationship with behavioural intention. Arab elderly users believed that the design of mobile health app UI was easy to use and effective to use. This usage would belief expected to strengthen their perception of the easiness of mHealth app UI. The flexibility in obtaining information, operating the application, and learning and managing medical information, provides a sense of relief to Arab elders on less effort exerted towards usage. Consequently, Agarwal and Karahanna [65] and Venkatesh [66], reiterate that successful deployment of mobile applications are based on how developers and designers ensure easiness towards actual use of apps Redzuan, Razali [67] and [68] also provided evidence that perceived ease of use has a significant effect on behavioural intention to use systems.

The relationship between ease of use and usefulness was also positive and significant within this study. The effect of perceived ease of use might contribute to clarifying a significant impact towards perceived usefulness. Usefulness of an application is tied to actual use. Where users are able to apply a particular technology to perform associated tasks, they relate to the performance of the technology in meeting task requirements. The ability of Arab elders in utilizing the mobile health app UI for health related purposes provided them with a sense of usefulness of the app. This is because, they derived benefits from the app in terms of acquiring useful health related information, diagnosis, prescriptions and awareness of ageing ailments' management and prevention. The acquisition of these benefits from the mobile app usage was dependent on their ability to interact with the app when demanded. Davis [28], posited that ease of use is an originator of usefulness. This result is also consistent with previous studies from Lallmahamood [69], Leishman [70], as well as Shim and Viswanathan [71].

Finally, the construct usefulness significantly influenced attitude towards usage of the mobile health app. Arab elderly users were interested in using the functionality of the mobile health app UI, which in turn increased their health related independence and helped them in their daily activities, ultimately improving their healthy life. The importance attached to the provisions of the mobile health app UI, made the users acquire a favourable affection towards the app. Their feelings were positive towards using the app because it benefited them in terms of provision of their health needs. In addition, usefulness had a significant effect on behavioural intention to use the mobile health app UI. As users became familiar with the use of the mobile health app, they found it helpful in their lives. How helpful the app was to them, culminated into positive intentions towards continual usage of the app. Arab elderly users' behavioural intentions to use the app was positive and highly reflected in their final usage behaviour. This result confirms the original TAM relationship between perceived usefulness and intention to adopt new technology. The result is also in line with several studies such as by [29, 30] who stated that usefulness was a strong factor for measuring the behavioural intention to use new systems.

\section{CONCLUSION AND IMPLICATIONS}

Mobile health apps could be a vital part for developing elderly people lives and decrease the cost of healthcare. This study attempted to enlarge the lack of research on the Arab elderly users' perspectives of mobile health app UI when culture is integrated into the design of mHealth application UI. Theoretically, this study evaluated the technology acceptance model (TAM) in the mobile health app UI context by investigating relationships between behavioural intention to use (BIU) and three independent factors perceived ease of use (PEOU), perceived usefulness (PU), and attitude towards use (ATU). The study identified the significant factors as being PU, PEUO and ATU. The results showed that most participants had a positive attitude towards using mobile health application UI designed based on Arab culture. However, this study provides support for TAM, and approved the fact that attitude is most powerful factor in explaining the behavioural intention toward usage.

\section{LIMITATIONS}

Nonetheless, there are some limitations that should be taken into account. First, the study's conceptual framework was constructed based on TAM only. This study can be further improved by other theoretical frameworks like Unified Theory of Acceptance and Use of Technology (UTAUT) to add to the analytical power of acceptance. Second, the present study investigated only the determinants of behavioural intention without exploiting that of actual behaviour.

\section{FUTURE WORK}

In the future, the researcher plans to continue exploring the relationship between certain design elements of UI, cultural aspects and mobile applications. Of particular interests are the following cultural aspects: Age, gender, religion and education level. This further exploration will be achieved by conducting future studies using mobile applications and theoretical frameworks like Unified Theory of Acceptance and Use of Technology (UTAUT).

\section{REFERENCES}

[1] Mamolo, M. and S. Scherbov, Population projections for forty-four European countries: The ongoing population ageing. 2009: Vienna Inst. of Demography.

[2] Roupa, Z., Nikas, M., Gerasimou, E., Zafeiri, V., Giasyrani, L., Kazitori, E., \& Sotiropoulou, P. (2010). The use of technology by the elderly. Health Science Journal, 4(2)..

[3] Boustani, S., Designing touch-based interfaces for the elderly. University of Sydney, Sydney, 2010.

[4] Vincent, G. and V. Velkoff, US Census Bureau. The next four decades: the older population in the United States: 2010 to 2050: population estimates and projections. May 2010. 2013.

[5] Shih, S.P., S. Yu, and H.C. Tseng, The Study of Consumers' Buying Behavior and Consumer Satisfaction in Beverages Industry in Tainan, Taiwan. Journal of Economics, Business and Management, 2015. 3(3): p. 391-394.

[6] Boulos, M.N.K., et al., How smartphones are changing the face of mobile and participatory healthcare: an overview, with example from eCAALYX. Biomedical engineering online, 2011. 10(1): p. 24. 
[7] Stinson, J.N., et al., Development and testing of a multidimensional iPhone pain assessment application for adolescents with cancer. Journal of medical Internet research, 2013. 15(3).

[8] Carter, M.C., et al., Adherence to a smartphone application for weight loss compared to website and paper diary: pilot randomized controlled trial. Journal of medical Internet research, 2013. 15(4).

[9] Turner-McGrievy, G.M., et al., Comparison of traditional versus mobile app self-monitoring of physical activity and dietary intake among overweight adults participating in an mHealth weight loss program. Journal of the American Medical Informatics Association, 2013. 20(3): p. 513-518.

[10] Kirwan, M., et al., Diabetes self-management smartphone application for adults with type 1 diabetes: randomized controlled trial. Journal of medical Internet research, 2013. 15(11).

[11] Cafazzo, J.A., et al., Design of an mHealth app for the self-management of adolescent type 1 diabetes: a pilot study. Journal of medical Internet research, 2012. 14(3).

[12] Khaddam, I., \& Vanderdonckt, J.. Towards a Culture-Adaptable UserInterface Architecture. Romanian Journal of Human-Computer Interaction, 2014. 7(2), 161.

[13] Kuerbis, A., et al., Older adults and mobile technology: Factors that enhance and inhibit utilization in the context of behavioral health. 2017.

[14] Foreman, K.F., et al., Impact of a text messaging pilot program on patient medication adherence. Clinical therapeutics, 2012. 34(5): p. 1084-1091.

[15] Olson, K.E., et al., Diffusion of technology: frequency of use for younger and older adults. Ageing international, 2011.36(1): p. 123-145.

[16] Hanson, V.L., Technology skill and age: what will be the same 20 years from now? Universal Access in the Information Society, 2011. 10(4): p. 443.

[17] Azir Rezha, N., Maksom, Z., \& Naim, C. P. Tackling design issues on elderly smartphone interface design using activity centered design approach. ARPN J. Eng. Appl, 2014. Sci, 9, 1190-1196.

[18] Alpay, L., et al., Current challenge in consumer health informatics: Bridging the gap between access to information and information understanding. Biomedical informatics insights, 2009. 2: p. BII. S2223.

[19] Mercer, K., et al., Using a collaborative research approach to develop an interdisciplinary research agenda for the study of mobile health interventions for older adults. JMIR mHealth and uHealth, 2015. 3(1).

[20] Levine, M. and M. Reid, D45: Primary care providers' perspectives on telemedicine in the pharmacologic management of older adults with chronic pain (cp). Journal of the American Geriatrics Society, 2012. 60: p. S202.

[21] Mitzner, T.L., et al., Older adults talk technology: Technology usage and attitudes. Computers in human behavior, 2010. 26(6): p. 1710-1721.

[22] Sibai, A.M., et al., Ageing and health in the Arab region: Challenges, opportunities and the way forward. Population Horizons, 2017.

[23] Saxena, P.C., Ageing and age-structural transition in the Arab countries: Regional variations, socioeconomic consequences and social security. Genus, 2008: p. 37-74.

[24] Khaddam, I. and J. Vanderdonckt, Towards a Culture-Adaptable UserInterface Architecture. Romanian Journal of Human-Computer Interaction, 2014. 7(2): p. 161.

[25] Van Biljon, J. and P. Kotzé, Cultural factors in a mobile phone adoption and usage model. J. UCS, 2008. 14(16): p. 2650-2679.

[26] Kalliny, M., et al., Cultural differences and similarities in television commercials in the Arab world and the United States. Journal of global marketing, 2011. 24(1): p. 41-57.

[27] Fishbein, M. and I. Ajzen, Belief, attitude, intention and behavior: An introduction to theory and research. 1975.

[28] Fishbein, M. and I. Ajzen, Belief, attitude, intention, and behavior: An introduction to theory and research. 1977.

[29] Davis, F.D., Perceived usefulness, perceived ease of use, and user acceptance of information technology. MIS quarterly, 1989: p. 319-340.

[30] Venkatesh, V., et al., User acceptance of information technology: Toward a unified view. MIS quarterly, 2003: p. 425-478.
[31] Al-Hujran, O. and M. Al-Dalahmeh. The role of national culture on citizen adoption of egovernment web sites. in ECEG2011-Proceedings of the 11th European Conference on EGovernment: ECEG2011. 2011. Academic Conferences Limited.

[32] Alharbi, S. and S. Drew, Using the technology acceptance model in understanding academics' behavioural intention to use learning management systems. International Journal of Advanced Computer Science and Applications, 2014. 5(1): p. 143-155.

[33] Al-Adwan, A., A. Al-Adwan, and J. Smedley, Exploring students acceptance of e-learning using Technology Acceptance Model in Jordanian universities. International Journal of Education and Development using Information and Communication Technology, 2013. 9(2): p. 4.

[34] Wingo, N. P., Ivankova, N. V., \& Moss, J. A. Faculty Perceptions about Teaching Online: Exploring the Literature Using the Technology Acceptance Model as an Organizing Framework. Online Learning, 2017. 21(1), 15-35.

[35] Lai, P. C. The literature review of technology adoption models and theories for the novelty technology. JISTEM-Journal of Information Systems and Technology Management, 2017. 14(1), 21-38.

[36] Shittu, A. T., Gambari, A. I., \& Sule, A. O. Students' attitude and behavioural intention on adoption of Internet for learning among $\mathrm{Al}$ Hikmah University Students in Nigeria: A test of technology acceptance model. Malaysian Journal of Distance Education, 2013.15(2), 89-107. Ocean University, 72

[37] Liu, Z. Y. An Analysis of Technology Acceptance Model-Exploring user acceptance and intension of taxi-hailing app in Shanghai, 2015. p. 206-215.

[38] Juniwati, J. Influence of perceived usefulness, ease of use, risk on attitude and intention to shop online. European Journal of Business and Management, 2014. 6, 218-229

[39] Alsamydai, M. J. Adaptation of the technology acceptance model (TAM) to the use of mobile banking services. International Review of Management and Business Research, 2017. 3(4), 2039.

[40] Guritno, S., \& Siringoringo, H. Perceived usefulness, ease of use, and attitude towards online shopping usefulness towards online airlines ticket purchase. Procedia-Social and Behavioral Sciences, 2013. 81, 212-216.

[41] Lai, J.-Y. and C.-C. Yang, Effects of employees' perceived dependability on success of enterprise applications in e-business. Industrial Marketing Management, 2009. 38(3): p. 263-274.

[42] Phua, P. L., Wong, S. L., \& Abu, R. Factors influencing the behavioural intention to use the internet as a teaching-learning tool in home economics. Procedia-Social and Behavioral Sciences, 2012.59, 180-187.

[43] Rathore, S., \& Panwar, A. Factors Influencing Behavioural Intention to use Smart Phones. Global Vistas, 2015. 19-28.

[44] Sek, Y.-W., et al., Prediction of user acceptance and adoption of smart phone for learning with technology acceptance model. Journal of Applied Sciences(Faisalabad), 2010. 10(20): p. 2395-2402.

[45] Redzuan, N. I. N., Razali, N. A., Muslim, N. A., \& Hanafi, W. N. W. Studying Perceived Usefulness and Perceived Ease of Use of Electronic Human Resource Management (e-HRM) with Behavior Intention. International Journal of Business, 2016.1(2).

[46] Lepper, M.R., Microcomputers in education: Motivational and social issues. American Psychologist, 1985. 40(1): p. 1.

[47] Moon, J.-W. and Y.-G. Kim, Extending the TAM for a World-WideWeb context. Information \& management, 2001. 38(4): p. 217-230.

[48] O'Cass, A. and T. Fenech, Web retailing adoption: exploring the nature of internet users Web retailing behaviour. Journal of Retailing and Consumer services, 2003. 10(2): p. 81-94.

[49] Wang, Y.-F. Modeling predictors of restaurant employees' green behavior: Comparison of six attitude-behavior models. International Journal of Hospitality Management, 2016.58, 66-81.

[50] Wang, W.-H. and Y.-J. Liu, Attitude, behavioral intention and usage: An empirical study of Taiwan Railway's internet ticketing system. Taiwan: National Taiwan Ocean University, 2009: p. 72.

[51] Azmi, A. and A. Alsaiari, Arabic typography: a survey. International Journal of Electrical \& Computer Sciences, 2010. 9(10): p. 1. 
[52] Hall, The theory of groups. Vol. 288. 1976: American Mathematical Soc.

[53] Hofstede, Culture's consequences: Comparing values, behaviors, institutions and organizations across nations. 2001: Sage.

[54] Ntaliani, M., C. Costopoulou, and S. Karetsos, Mobile government: A challenge for agriculture. Government Information Quarterly, 2008. 25(4): p. 699-716.

[55] Drost, E.A., Validity and reliability in social science research. Education Research and perspectives, 2011. 38(1): p. 105.

[56] Cho, E., \& Kim, S. Cronbach's coefficient alpha: Well known but poorly understood. Organizational Research Methods, 2015.18(2), 207230.

[57] Hauke, J., \& Kossowski, T. Comparison of values of Pearson's and Spearman's correlation coefficients on the same sets of data. Quaestiones geographicae, 2011. 30(2), 87-93.

[58] Field, A., Discovering statistics using IBM SPSS statistics. 2013: sage.

[59] Kock, N., Non-normality propagation among latent variables and indicators in PLS-SEM simulations. Journal of Modern Applied Statistical Methods, 2016. 15(1): p. 16.

[60] Alotaibi, R., L. Houghton, and K. Sandhu, Factors Influencing Users" Intentions to Use Mobile Government Applications in Saudi Arabia: TAM Applicability. international journal of advanced computer science and applications, 2017. 8(7): p. 200-211.

[61] Fong, K.K.-K. and S.K.S. Wong, Factors influencing the behavior intention of mobile commerce service users: An exploratory study in Hong Kong. International Journal of Business and Management, 2015. 10(7): p. 39

[62] Burton-Jones, A. and G.S. Hubona, Individual differences and usage behavior: revisiting a technology acceptance model assumption. ACM SIGMIS Database: the DATABASE for Advances in Information Systems, 2005. 36(2): p. 58-77.
[63] Almakky, H., R. Sahandi, and J. Taylor, The Effect of Culture on User Interface Design of Social Media-A Case Study on Preferences of Saudi Arabians on the Arabic User Interface of Facebook. World Academy of Science, Engineering and Technology International Journal of Social, Behavioral, Educational, Economic, Business and Industrial Engineering, 2015. 9(1): p. 107-111.

[64] Ishak, Z., A. Jaafar, and A. Ahmad, Interface design for cultural differences. Procedia-Social and Behavioral Sciences, 2012. 65: p. 793801.

[65] Agarwal, R. and E. Karahanna, Time flies when you're having fun: Cognitive absorption and beliefs about information technology usage. MIS quarterly, 2000: p. 665-694.

[66] Venkatesh, V., Creation of favorable user perceptions: exploring the role of intrinsic motivation. MIS quarterly, 1999: p. 239-260.

[67] Redzuan, N.I.N., et al., Studying Perceived Usefulness and Perceived Ease of Use of Electronic Human Resource Management (e-HRM) with Behavior Intention. International Journal of Business, 2016. 1(2).

[68] Revythi, A. and N. Tselios, Extension of Technology Acceptance Model by using System Usability Scale to assess behavioral intention to use elearning. arXiv preprint arXiv:1704.06127, 2017.

[69] Lallmahamood, M., An Examination of Individual's Perceived Security and Privacy of the Internet in Malaysia and the Influence of this on their Intention to Use E-commerce: Using an Extension of the Technology Acceptance Model. Journal of Internet Banking and Commerce, 2007. 12(3): p. 1

[70] Leishman, P., Understanding the Unbanked Customer and Sizing the Mobile Money Opportunity. GSMA Mobile Money for the Unbanked Annual Report 2009, 2010.

[71] Shim, S.J. and V. Viswanathan, User assessment of personal digital assistants used in pharmaceutical detailing: system features, usefulness and ease of use. Journal of Computer Information Systems, 2007. 48(1): p. 14-21. 